\title{
Effects of sludge properties in a combined process of mesophilic anaerobic digestion and thermophilic aerobic digestion
}

\author{
Zehua Zhao ${ }^{1}$, Yuanshun $\mathrm{Xu}^{1}$, Tianfeng Wang ${ }^{2}$, Xiaowei Xu ${ }^{1 *}$, Houhu Zhang ${ }^{1}$, and Jing Hua ${ }^{1}$ \\ ${ }^{1}$ Nanjing Institute of Environmental Science, Ministry of Ecology and Environment of China, Nanjing, 210042, P.R.China \\ ${ }^{2}$ School of Chmistry and Environmental Engineering, Jiu Jiang University, JiuJiang 332005, P.R.China
}

\begin{abstract}
The combination of mesophilic anaerobic digestion and thermophilic aerobic digestion (MANTAD) has been recognized as a suitable technology to deal with conventional activated sludge. The MANTAD system can make sludge achieve better stability. The retention time of anaerobic digestion (AD-time) had an important role in the sludge stabilization process. With the extension of anaerobic digestion retention time, MAN-TAD system can make sludge achieve better stability. In comparison, volatile/total solids ratio (VS/TS) at AD-time of $38 \mathrm{~d}$ presented the lowest values among the three different AD-time with the value of 0.32 . Long retention time of anaerobic digestion resulted in high amounts of soluble organic compounds (SCOD), and extracellular polymers (EPS) in the supernatant. Such high amount of organic compounds caused deterioration in sludge dewaterability. Compared with sludges of AD-time $17 \mathrm{~d}$ and $24 \mathrm{~d}$, sludge of AD-time $38 \mathrm{~d}$ became extremely difficult to dewater due to its high capillary water absorption time (CST) at the end of digestion.
\end{abstract}

\section{Introduction}

Conventional activated sludge process is the most widely used wastewater biological treatment process[1]. However, conventional activated sludge process will produce a lot of sludge which is difficult to stabilize and dewater[2]. Biological treatment methods, including aerobic and anaerobic digestion processes, are usually used to stabilize sludge before final disposal. Among these methods, the combination of mesophilic anaerobic digestion and thermophilic aerobic digestion has been recognized as a suitable technology to solve this problem because of its low cost and simple operation[3].

In recent years, the combination of mesophilic anaerobic digestion and thermophilic aerobic digestion has been further improved to simplify application and save aeration energy[4]. Meanwhile, some factors affect the combination process, one of which is the retention time of anaerobic digestion[5,6]. Previous researchers have pointed out that altering the retention time of anaerobic digestion can affect the efficiency of MANTAD[7]. Therefore, it is necessary to study the retention time of anaerobic digestion carefully to find a proper operation mode, and controlled to prevent upsetting the digester by prolonging or shortening anaerobic digestion time.

The primary purpose of sludge stabilization is to degrade the organic matter contained in sludge and kill microorganisms and pathogens $[8,9]$. For this reason, the concept of stability is often related to that of putrescibility and odour, too. The volatile/total solids ratio can be used as a stability index[10]. Ratios below 0.40 , generally, give an indication of achieved stabilization[11]. Previous studies have found that many factors, including the retention time of anaerobic digestion, will affect the stability of sludge[12, 13].

Sludge dewatering is the key to sludge reduction[4]. However, some researchers have pointed out that sludge mixture is difficult to dewater because of its complex structure and hydrophilic substances such as microbial cells and extracellular polymers[5]. Therefore, it is necessary to further study the sludge dewatering performance of the combination of mesophilic anaerobic digestion and thermophilic aerobic digestion.

This work aims to determine the appropriate retention time of anaerobic digestion and achieve stabilization during MAN-TAD process. According to the obtained results of optimum operation parameters and fundamental theories of anaerobic and aerobic digestions, batch experiments are performed at different AD-times of $17 \mathrm{~d}, 24 \mathrm{~d}$, and $38 \mathrm{~d}$. Meanwhile, this work investigates volatile solids removal and dewatering characteristics of conventional activated sludge, and analyses the variation of sludge properties before and after the digestion treatment. The purpose of this work is to evaluate the performance of MAN-TAD and provide suggestions for its large-scale application.

\section{Materials and methods}

\footnotetext{
* Corresponding author: xuxiaowei@nies.org
} 


\subsection{Sludge samples}

The sludge used in the experiment was taken from the sewage treatment plant of Jiujiang University, which used sequencing batch process (SBR) to treat domestic sewage. Their characteristics are shown in Table 1. The total solid (TS), volatile solid (VS), $\mathrm{NH}^{4+}-\mathrm{N}$ and $\mathrm{pH}$ value were determined according to the standard method[14]. The capillary water absorption time was measured by Triton 304 CST tester.

Table 1. Sludge parameters

\begin{tabular}{|c|c|}
\hline Parameters & Results \\
\hline $\mathrm{pH}$ & $6.43 \pm 0.05$ \\
\hline $\mathrm{NH}^{4+}-\mathrm{N}$ & $47.3 \pm 4.5 \mathrm{mg} / \mathrm{L}$ \\
\hline $\mathrm{SCOD}$ & $104.5 \pm 6.3 \mathrm{mg} / \mathrm{L}$ \\
\hline $\mathrm{TS}$ & $26100 \pm 300 \mathrm{mg} / \mathrm{L}$ \\
\hline $\mathrm{VS}$ & $11900 \pm 100 \mathrm{mg} / \mathrm{L}$ \\
\hline $\mathrm{CST}$ & $4.3 \pm 2.0 \mathrm{~s} / \mathrm{g}$ \\
\hline
\end{tabular}

\subsection{Experimental setup}

$500 \mathrm{~mL}$ of sludge solution was placed in an anaerobic reactor in a constant temperature water bath at $55 \pm 2{ }^{\circ} \mathrm{C}$ for 17 days, 24 days and 38 days, respectively. After anaerobic digestion, the sludge solution was transferred to an aerobic reactor with a constant temperature water bath at $35 \pm 2{ }^{\circ} \mathrm{C}$ for aeration. After the specified time of aerobic aeration $(1 \mathrm{~d}, 3 \mathrm{~d}, 5 \mathrm{~d}, 8 \mathrm{~d}$ and $15 \mathrm{~d})$, samples were taken to determine TS, VS, $\mathrm{pH}, \mathrm{NH}^{4+}-\mathrm{N}, \mathrm{CST}$ and EPS.

\subsection{EPS extraction and analysis}

EPS was extracted by heating. The extraction method is as follows: take $4 \mathrm{~mL}$ of sludge into a centrifuge tube, centrifugate it at $4000 \mathrm{~g} / \mathrm{min}$ for $5 \mathrm{~min}$, and the supernatant is slim; add $0.05 \% \mathrm{NaCl}$ solution into the centrifuge tube to the original mass, shake it well, and then take a water bath at $50{ }^{\circ} \mathrm{C}$ for $5 \mathrm{~min}$, then centrifugate it at $4000 \mathrm{~g} / \mathrm{min}$ for $10 \mathrm{~min}$, and the supernatant is LB-EPS.

Prior to chemical analysis, the supernatant of sludge sample was filtered through a $0.45 \mathrm{~mm}$ filter. The content of polysaccharide in EPS was determined by anthrone sulfuric acid method with glucose as standard[15]; the content of protein and humic substance was determined by modified Lowry method with egg protein and humic acid as standard[16].

\section{Results and discussion}

\subsection{Variation of $\mathrm{pH}$ and $\mathrm{NH}^{4+}-\mathrm{N}$ at different $\mathrm{AD}$ - times}

The effects of different AD-times (17 d, $24 \mathrm{~d}$, and $38 \mathrm{~d}$ ) on $\mathrm{pH}$ are shown in Figure 1. The $\mathrm{pH}$ of the digester was not regulated in these batch-operation experiments. In the initial $3 \mathrm{~d}$ of anaerobic digestion, the $\mathrm{pH}$ decreased with increasing retention time because of the effect of hydrolytic-acidification[17]; then gradually increased to higher than 7.8, which was due to the release of protein by cytolysis, which produced a large amount of $\mathrm{NH}^{4+}-\mathrm{N}$ through deamination.

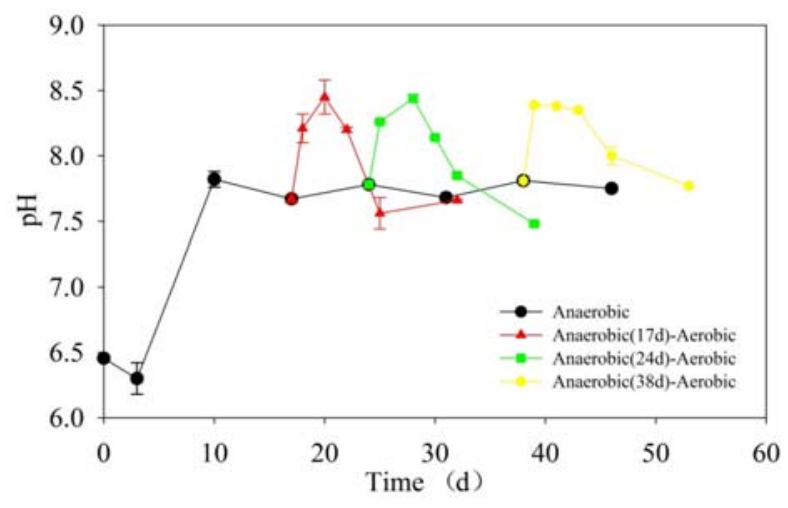

Figure 1. Variation of $\mathrm{pH}$ at different $\mathrm{AD}$-times

The $\mathrm{pH}$ at different AD-times (17 d, $24 \mathrm{~d}$, and $38 \mathrm{~d}$ ) increased continuously in the first 3 days, reaching the maximum values of $8.4,8.3$, and 8.4 , respectively. After reaching the maximum values, the $\mathrm{pH}$ sharply declined to less than 7.8 in the next 4 days. Previous researchers have pointed out that $\mathrm{pH}$ value is related to the hydrolysis release of reduced nitrogen and subsequent acid-base transformation[18]. The $\mathrm{pH}$ of MAN-TAD system was usually alkaline, which was consistent with the law of one-stage ATAD studied by other researchers. However, $\mathrm{pH}$ of the combined process of mesophilic anaerobic digestion and thermophilic aerobic digestion system is complex and affected by many factors[19]. In fact, the pasteurization effect of the combined process is due to temperature, but also due to the increased $\mathrm{pH}$ value in the treatment process[20].

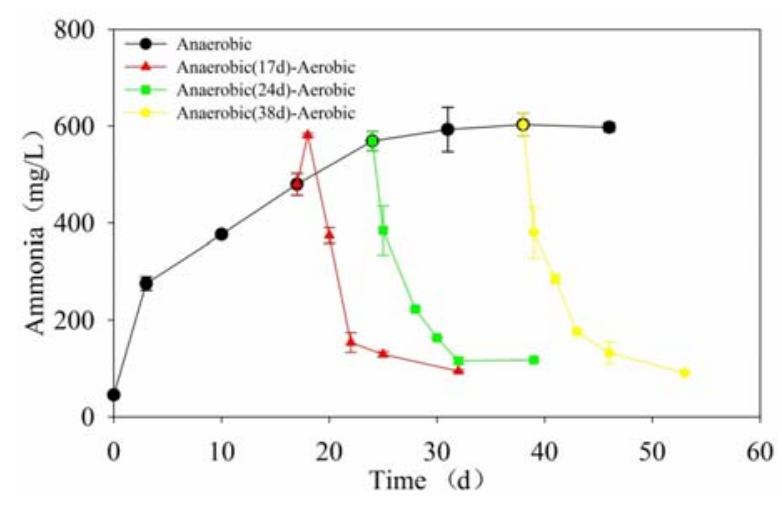

Figure 2. Variation of $\mathrm{NH}^{4+}-\mathrm{N}$ at different $\mathrm{AD}$-times

Variations of contents of $\mathrm{NH}^{4+}-\mathrm{N}$ in the supernatant at different $\mathrm{AD}$-times are shown in Figures 2. From 
Figure 2, the $\mathrm{NH}^{4+}-\mathrm{N}$ content increased continuously in the first 30 days, reaching the maximum value of $569.1 \pm$ $20.0 \mathrm{mg} / \mathrm{L}$ and retaining to the end of the anaerobic digestion. When aerobic digestion begins, the concentration of $\mathrm{NH}^{4+}-\mathrm{N}$ at different AD-times $(17 \mathrm{~d}, 24$ $\mathrm{d}$, and $38 \mathrm{~d}$ ) sharply declined to less then $100 \mathrm{mg} / \mathrm{L}$, indicating that $\mathrm{NH}^{4+}-\mathrm{N}$ were used in thermophilic aerobic digestion. Previous researchers have pointed out that denitrification and nitrification were inhibited with little loss of nitrogen as nitrogen in the combined process of mesophilic anaerobic digestion and thermophilic aerobic digestion system[21]. Aeration can reduce the contents of $\mathrm{NH}^{4+}-\mathrm{N}$ in the supernatant by removing the produced $\mathrm{NH}_{3}$. The surplus soluble $\mathrm{NH}^{4+}-\mathrm{N}$ was actually dissolved in the sludge water, and reaches the dynamic balance on the basis of the reaction: $\mathrm{NH}_{3}+\mathrm{H}_{2} \mathrm{O} \Leftrightarrow \mathrm{NH}^{4+}$ $+\mathrm{OH}^{-}$, which improves the $\mathrm{pH}$ value of the AD-TAN system.

\subsection{Variation of SCOD at different AD-times}

The result of SCOD in the supernatant for the MANTAD is shown in Figure 3. As shown in Figure 3, SCOD concentrations sharply increased to the highest values of $2000 \mathrm{mg} / \mathrm{L}$ in the first 3 days of anaerobic digestion. After maintaining the high value for 3 days, SCODs began to decrease, and gradually showed slight fluctuation in the later stage of digestion. Compared with other curves, SCOD at AD-Time $17 \mathrm{~d}$ showed the highest values after 15 days of thermophilic aerobic digestion because of the high number of microorganisms. According to previous studies, a large number of intercellular organic substances, including some thermostable enzymes, were released into the supernatant due to endogenous decay and enhanced cell wall dissolution, which led to a sharp increase in the concentration of SCOD[22]. With the start of aerobic digestion, aerobic bacteria rapidly proliferated and consumed the organic matter in the supernatant, resulting in a rapid reduction of the organic matter in the reactor, as suggested by the SCOD decline in the post digestion period.

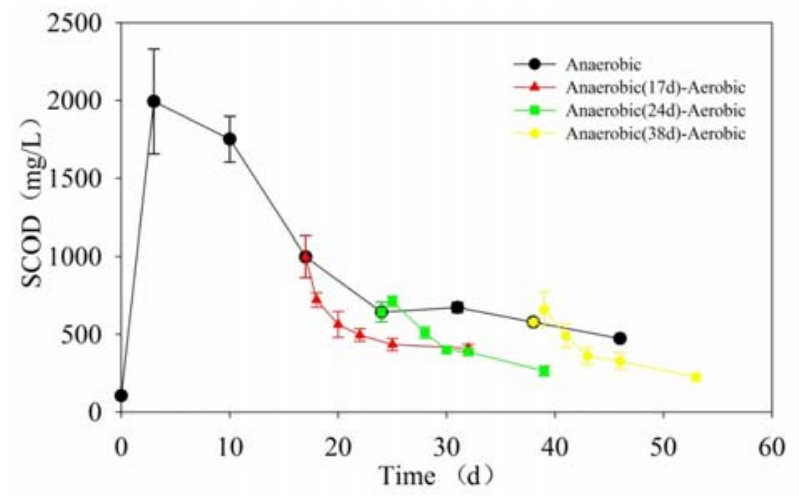

Figure 3. Variation of SCOD at different AD-times

3.3 Variation of CST at different AD-times
EPS have been found to play an important role in sludge dewatering process[23]. EPS govern sludge properties, like surface charge, hydrophobicity, bound water content and floc strength. Sludge containing compact flocs without single cells and dissolved EPS had high dewaterability[24]. The release of excessive EPS showed a negative effect on sludge dewatering. The protein-like polymers in EPS might be responsible for worse dewaterability after microwave treatment. It was also found that the characteristics of EPS were more important than their quantity in sludge dewatering[25]. The variation of normalized ESP at different AD-times are shown in Figure 4.

As shown in Figure 4, protein and polysaccharide concentrations sharply increased to the highest values of $32 \mathrm{mg} / \mathrm{g}$ and $6.8 \mathrm{mg} / \mathrm{g}$ in the first 3 days of anaerobic digestion. After reaching the maximum values, protein and polysaccharide concentrations declined to less than $15 \mathrm{mg} / \mathrm{g}$ and $5 \mathrm{mg} / \mathrm{g}$ in the next 15 days. Protein and polysaccharide concentrations at different AD-times (17 $\mathrm{d}, 24 \mathrm{~d}$, and $38 \mathrm{~d}$ ) increased continuously in the first 3 days, reaching the maximum values and retaining to the end of the aerobic digestion.

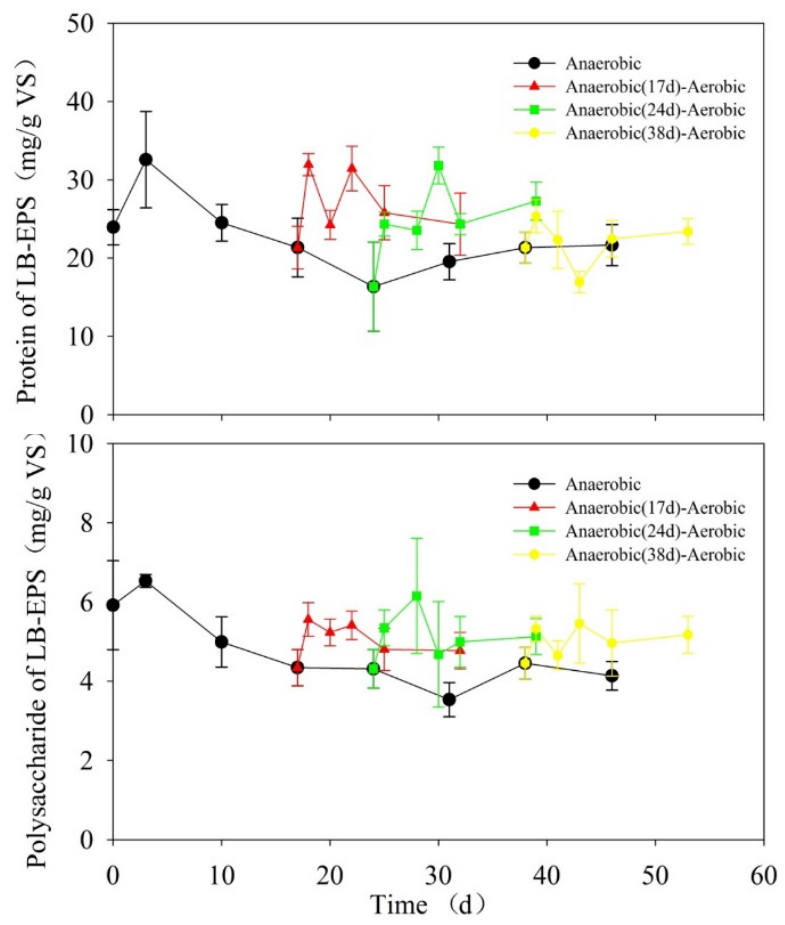

Figure 4. Variation of EPS at different AD-times

Sludge dewatering is the key to sludge reduction. According to previous studies, sludge mixture is difficult to dewater because of its complex structure and hydrophilic substances such as microbial cells and extracellular polymers[26]. The normalized capillary water absorption time provides a simple, fast and cheap way to measure the dewatering potential of sludge. The variation of normalized CST at different AD-times are shown in Figure 4.

As shown in Figure 5, CSTs at different AD-times gradually increased with prolonged digestion time, indicating that all sludge becomes difficult to dewater 
after digestion. Compared with sludges of AD-time $17 \mathrm{~d}$ and $24 \mathrm{~d}$, Sludge of AD-time $38 \mathrm{~d}$ became extremely difficult to dewater due to its high CST at the end of digestion. CST at AD-time of $38 \mathrm{~d}$ increased 2.7 times at the end of aerobic digestion. However, CST at AD-time of $17 \mathrm{~d}$ was relatively low throughout the digestion process and still maintained the value at $46.69 \pm 4.1 \mathrm{~s} / \mathrm{g}$. some researchers have pointed out that sludge mixture is difficult to dewater because of its complex structure and hydrophilic substances such as microbial cells and extracellular polymers[27]. In addition, strong correlation was noted between normalized CST and EPS. Int his work, sludge with a TS of 38 with poor dewaterability showed high EPS concentration in the supernatant in the MAN-TAD system.

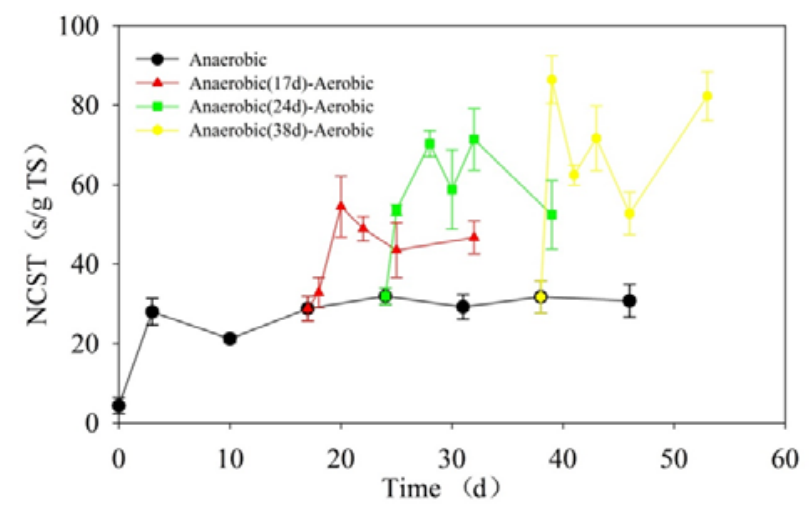

Figure 5. Variation of CST at different AD-times

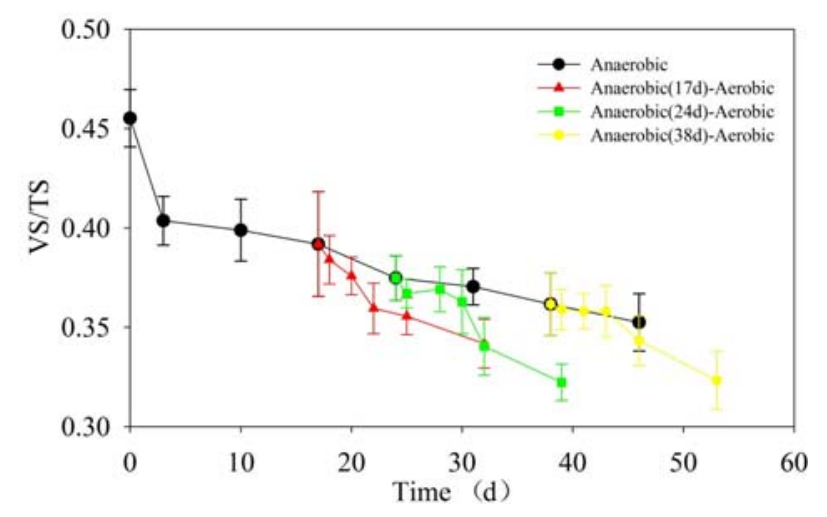

Figure 6. Variation of VS/TS at different AD-times

\subsection{Variation of VS/TS at different AD-times}

The primary purpose of sludge stabilization is to degrade the organic matter contained in sludge and kill microorganisms and pathogens[28]. For this reason, the concept of stability is often related to that of putrescibility and odour, too. VS/TS can be used as a stability index. Ratios below 0.40 , generally, give an indication of achieved stabilization. The variation of $\mathrm{VS} / \mathrm{TS}$ at different AD-times are shown in Figure 5.

As shown in Figure 5, VS/TS sharply decreased to 0.41 in the first 3 days of anaerobic digestion. The slow average removal rate decreased by $0.11 \%$ per day from 3 to $46 \mathrm{~d}$, with a minimum value of 0.36 . At $\mathrm{AD}$-time of $17 \mathrm{~d}$, VS/TS decreased to 0.34 after 15 days of thermophilic aerobic digestion. The VS/TS at AD-time of $24 \mathrm{~d}$ and $38 \mathrm{~d}$ were relatively lower, indicating that short AD-time contributed to less energy in MAN-TAD system. In comparison, VS/TS at AD-time of $38 \mathrm{~d}$ presented the lowest values among the three different AD-time with the value of 0.32 . The results showed that with the extension of anaerobic digestion retention time, MAN-TAD system can make sludge achieve better stability.

\section{4 conclusion}

The MAN-TAD system can make sludge achieve better stability. The retention time of anaerobic digestion had an important role in the sludge stabilization process.

(1) Long retention time of anaerobic digestion resulted in high amounts of soluble organic compounds of SCOD, and EPS in the supernatant. Such high amount of organic compounds caused deterioration in sludge dewaterability. Compared with sludges of AD-time $17 \mathrm{~d}$ and $24 \mathrm{~d}$, Sludge of AD-time $38 \mathrm{~d}$ became extremely difficult to dewater due to its high CST at the end of digestion.

(2) With the extension of anaerobic digestion retention time, MAN-TAD system can make sludge achieve better stability. In comparison, VS/TS at ADtime of $38 \mathrm{~d}$ presented the lowest values among the three different AD-time with the value of 0.32 .

\section{Reference}

1. Y. Zhu, K. Xiao, Y. Zhou, W. Yu, S. Tao, C. Le, D. Lu, Z. Yu, S. Liang, J. Hu, H. Hou, B. Liu, J. Yang, Profiling of amino acids and their interactions with proteinaceous compounds for sewage sludge dewatering by Fenton oxidation treatment, Water Res 175 (2020) 115645.

2. P. Wu, J. Yi, L. Feng, X. Li, Y. Chen, Z. Liu, S. Tian, S. Li, S. Khan, Y. Sun, Microwave assisted preparation and characterization of a chitosan based flocculant for the application and evaluation of sludge flocculation and dewatering, Int $\mathrm{J}$ Biol Macromol 155 (2020) 708-720.

3. R.H. Ramachandra, C.P. Devatha, Experimental investigation on sludge dewatering using granulated blast furnace slag as skeleton material, Environ Sci Pollut Res Int 27(11) (2020) 11870-11881.

4. H. Masihi, G. Badalians Gholikandi, Using acidicmodified bentonite for anaerobically digested sludge conditioning and dewatering, Chemosphere 241 (2020) 125096.

5. H. Lv, S. Xing, D. Liu, F. Wang, W. Zhang, G. Sun, $\mathrm{X}$. $\mathrm{Wu}$, Soluble metal ions migration and distribution in sludge electro-dewatering, Environ Res 180 (2020) 108862.

6. X. Liu, J. Wang, E. Liu, T. Yang, R. Li, Y. Sun, Municipal sludge dewatering properties and heavy 
metal distribution: Effects of surfactant and hydrothermal treatment, Sci Total Environ 710 (2020) 136346.

7. N. Lin, W. Zhu, X. Fan, C. Wang, C. Chen, H. Zhang, L. Chen, S. Wu, Y. Cui, Key factor on improving secondary advanced dewatering performance of municipal dewatered sludge: Selective oxidative decomposition of polysaccharides, Chemosphere 249 (2020) 126108.

8. Y. Tang, X. Dai, B. Dong, Y. Guo, L. Dai, Humification in extracellular polymeric substances (EPS) dominates methane release and EPS reconstruction during the sludge stabilization of high-solid anaerobic digestion, Water Res 175 (2020) 115686.

9. C. Reyes-Contreras, P. Neumann, F. Barriga, M. Venegas, C. Dominguez, J.M. Bayona, G. Vidal, Organic micropollutants in sewage sludge: influence of thermal and ultrasound hydrolysis processes prior to anaerobic stabilization, Environ Technol 41(11) (2020) 1358-1365.

10. X. Mei, J. Tang, Y. Zhang, Sludge stabilization: Characteristics of the end-products and an alternative evaluative methodology, Waste Manag 105 (2020) 355-363.

11. S. Liu, M. Wu, X. Yao, Effects of reactive oxygen species scavengers on thermophilic micro-aerobic digestion for sludge stabilization, Environ Res 185 (2020) 109453.

12. H. Dastpak, H. Pasalari, A.J. Jafari, M. Gholami, M. Farzadkia, Improvement of Co-Composting by a combined pretreatment Ozonation/Ultrasonic process in stabilization of raw activated sludge, Sci Rep 10(1) (2020) 1070.

13. H. Chen, H. Yuan, L. Mao, M.Z. Hashmi, F. Xu, X. Tang, Stabilization/solidification of chromiumbearing electroplating sludge with alkali-activated slag binders, Chemosphere 240 (2020) 124885.

14. D.Q. He, J.Y. Chen, B. Bao, X.L. Pan, J. Li, C. Qian, H.Q. Yu, Optimizing sludge dewatering with a combined conditioner of Fenton's reagent and cationic surfactant, J Environ Sci (China) 88 (2020) 21-30.

15. X. Han, S. Zhang, S. Yang, L. Zhang, Y. Peng, Fullscale partial nitritation/anammox (PN/A) process for treating sludge dewatering liquor from anaerobic digestion after thermal hydrolysis, Bioresour Technol 297 (2020) 122380.

16. J. Guo, X. Wen, Performances and mechanisms of sludge dewatering by a biopolymer from piggery wastewater and application of the dewatered sludge in remediation of $\mathrm{Cr}(\mathrm{VI})$-contaminated soil, $\mathrm{J}$ Environ Manage 259 (2020) 109678.

17. J. Guo, Q. Gao, S. Jiang, Insight into dewatering behavior and heavy metals transformation during waste activated sludge treatment by thermallyactivated sodium persulfate oxidation combined with a skeleton builder-wheat straw biochar, Chemosphere 252 (2020) 126542.
18. D. Ge, C. Bian, H. Yuan, N. Zhu, An in-depth study on the deep-dewatering mechanism of waste activated sludge by ozonation pre-oxidation and chitosan re-flocculation conditioning, Sci Total Environ 714 (2020) 136627.

19. M. Ettoumi, M. Jouini, C.M. Neculita, S. Bouhlel, L. Coudert, I. Haouech, M. Benzaazoua, Characterization of Kef Shfeir phosphate sludge (Gafsa, Tunisia) and optimization of its dewatering, J Environ Manage 254 (2020) 109801.

20. G. Acosta-Santoyo, A. Raschitor, E. Bustos, J. Llanos, P. Canizares, M.A. Rodrigo, Electrochemically assisted dewatering for the removal of oxyfluorfen from a coagulation/flocculation sludge, J Environ Manage 258 (2020) 110015.

21. J. Zhang, Q. Hu, J. Lu, S. Lin, Study on the effect of chitosan conditioning on sludge dewatering, Water Sci Technol 79(3) (2019) 501-509.

22. Z.X. Xu, H. Song, X.Q. Deng, Y.Y. Zhang, M. XueQin, S.Q. Tong, Z.X. He, Q. Wang, Y.W. Shao, X. $\mathrm{Hu}$, Dewatering of sewage sludge via thermal hydrolysis with ammonia-treated Fenton iron sludge as skeleton material, J Hazard Mater 379 (2019) 120810.

23. B.J. Ward, J. Traber, A. Gueye, B. Diop, E. Morgenroth, L. Strande, Evaluation of conceptual model and predictors of faecal sludge dewatering performance in Senegal and Tanzania, Water Res 167 (2019) 115101.

24. M. Song, M. Li, Adsorption and regeneration characteristics of phosphorus from sludge dewatering filtrate by magnetic anion exchange resin, Environ Sci Pollut Res Int 26(33) (2019) 34233-34247.

25. B. Rao, X. Su, S. Qiu, P. Xu, X. Lu, M. Wu, J. Zhang, Y. Zhang, W. Dong, Meso-mechanism of mechanical dewatering of municipal sludge based on low-field nuclear magnetic resonance, Water Res 162 (2019) 161-169.

26. B. Rao, X. Su, X. Lu, Y. Wan, G. Huang, Y. Zhang, P. Xu, S. Qiu, J. Zhang, Ultrahigh pressure filtration dewatering of municipal sludge based on microwave pretreatment, J Environ Manage 247 (2019) 588-595.

27. C.A. Quist-Jensen, L. Wybrandt, H. Lokkegaard, S.B. Antonsen, M.L. Christensen, Pilot-scale study for phosphorus recovery by sludge acidification and dewatering, Environ Technol (2019) 1-7.

28. H. Zhong, X. Liu, L. Zhu, Y. Yang, S. Yan, X. Zhang, Bioelectrochemically-assisted vermibiofilter process enhancing stabilization of sewage sludge with synchronous electricity generation, Bioresour Technol 289 (2019) 121740. 